\title{
Agility in the Archives: Translating Agile Methods to Archival Project Management
}

\begin{abstract}
"Agility in the Archives" affirms the importance of project management in special collections and archives, demonstrating how agile project management methods can augment success in archival processing projects. Shein, Robinson, and Gutierrez present criteria commonly used to measure project success and examine agile project management factors that have been correlated with project success in other disciplines. The authors introduce agile principles and provide practical insight on how agile factors can be adopted to support project success in archives. Drawing examples from a grant-funded project completed by the University of Nevada, Las Vegas (UNLV) University Libraries, the authors establish parallels between efficient iterative archival processing and agile project management methods. The study calls archivists to look beyond the details of archival processing techniques and to approach archival processing projects holistically.
\end{abstract}

Every year, state and federal funding agencies award millions of U.S. dollars to libraries, archives, and museums to support important work. A high level of project success is expected, and failure to meet performance objectives can be costly. Project management theories are designed to increase the odds of success, and some of these theories are presented in information science literature. The literature confirms that "project management is now a core activity for many library and

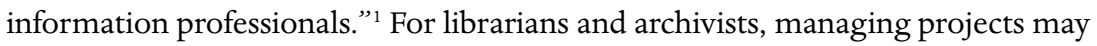
be just one of their many responsibilities, but project management is a discipline in its own right. ${ }^{2}$ Project management is complex, strategic, and tactical; perhaps most important, it is about people. "Project management is a matter of vision, determination, and the ability to appreciate the men and women who can turn that vision and determination into physical realities." ${ }^{3}$ Project management considers all components of a project holistically—from its conception to its people, planning,

1. Barbara Allan, Project Management: Tools and Techniques for Today's ILS Professional (London: Facet, 2004), 184. See literature review for additional authors on this point.

2. Some libraries and archives have full-time personnel who are dedicated project managers, but no literature was found to suggest a common practice of hiring certified project managers to manage archival processing projects.

3. Charles L. Buck, "Managing the Most Valuable Resource: People," Project Management Quarterly 8, no. 2 (1977).

๑ 2018 by Cyndi Shein, Hannah E. Robinson, and Hana Gutierrez (CC BY-NC [https:// creativecommons.org/licenses/by-nc/4.0/]). 
execution, and closing. The literature suggests that, although information professionals are successfully managing archival projects, they are concerned more about the details of archival processing (primarily arrangement and description) than with the project's overall management.

Reputable professionals, such as Gordon Daines, Dan Santamaria, and Chris Prom, have made persuasive arguments in favor of a holistic approach to archival program management. ${ }^{4}$ Similarly, this paper advocates for a more holistic approach to archival processing projects. Reports on successfully completed projects suggest that archivists are in fact implementing sound, possibly holistic, project management strategies, but they have not published studies on their project management experiences. Implementations of project management methods are discussed in the context of library projects and digital projects related to archives and special collections. However, studies on the implementation of archival processing projects tend to concentrate on one aspect of a project's execution rather than considering the entire endeavor.

Rather than focusing a microscope on archival processing techniques, this study steps back to examine archival project planning and execution through a wider lens. The authors reflect on an archival processing project, America's Great Gamble: A Project to Promote the Discovery of Sources about the Expansion of Legalized Gambling across the United States, which was recently completed by the University of Nevada, Las Vegas (UNLV) University Libraries Special Collections and Archives Division. In retrospect, the UNLV project team realized that, although they initiated the project using a traditional project management model, they instinctively and unconsciously assimilated concepts and practices from the realm of agile project management. This paper affirms the importance of project management in special collections and archives, demonstrating how agile project methods can augment success in archival processing projects.

Agile project management methods are most often discussed in the context of software development, the industry by which it has been most widely embraced. Agile methods are often explained in contrast to traditional methods. Traditional project management processes are performed in five distinct sequential phases: initiating, planning, executing, monitoring and controlling, and closing. ${ }^{5}$ Traditional project man-

4. J. Gordon Daines III, "Re-engineering Archives: Business Process Management (BPM) and the Quest for Archival Efficiency," American Archivist 74 (Spring/Summer 2011): 123-57; the sixth principle of an extensible processing program is "Approach processing holistically," Daniel A. Santamaria, Extensible Processing for Archives and Special Collections: Reducing Processing Backlogs (Chicago, Ill.: ALA: Neal-Schuman, 2015), 16; Christopher J. Prom, "Optimum Access? Processing in College and University Archives," American Archivist 73 (Spring/Summer 2010): 146-74.

5. For more information, see the Project Management Institute, a nonprofit organization of project management professionals online at https:/ / www.pmi.org/about/learn-about-pmi/what-is-projectmanagement [accessed 2 February 2018]. 
agement strives to avoid change, which can cost time and money. In contrast, an agile approach expects and manages change, rather than trying to prevent it. ${ }^{6}$ By embracing new ideas as a project progresses, agile methods integrate planning with execution. An agile project begins with a sound, but not necessarily detailed, project plan and relies on project team members to enhance the initial plan throughout the project period. While traditional methods focus on budget, schedule, and scope, agile methods prioritize deliverables and the product's value to end users and the organization. ${ }^{7}$

As with any theory, interpretations and implementations vary, but truly agile methodologies exhibit some essential characteristics:

Agile project management is an approach based on delivering requirements iteratively and incrementally throughout the project life cycle. At the core of agile is the requirement to exhibit central values and behaviours of trust, flexibility, empowerment and collaboration. ${ }^{8}$

The central values of the agile approach gained momentum in the software industry following the publication of the Manifesto for Agile Software Development in 2001. ${ }^{9}$ The values were then interpreted as different software development frameworks such as Scrum, Kanban, extreme programming (XP), feature-driven development (FDD), and others. As early as 2014, studies began to suggest that the principles of agile project management are applicable to industries beyond software development. ${ }^{10}$ When the UNLV team assessed their project, they concluded that its core values, conditions, and practices were closely aligned with an agile approach. Their unintentionally agile-style project management enabled the confluence of plans, people, and processes that supported efficiencies and high-quality deliverables.

Following this introduction, readers will find a description of the authors' research methodology, a review of literature in the library and archives profession, and background on the UNLV project, America's Great Gamble. Built on this foundational information, the body of the paper then demonstrates the intersection

6. Michael Karlesky and Mark Vander Voord, "Agile Project Management (or, Burning Your Gantt Charts)" (paper presented at the Embedded Systems Conference Boston, October 2008, Boston, Massachusetts), available online at https: / / atomicobject.com/uploads/archive/files/EmbeddedAgilePMPaper.pdf [accessed 12 January 2018].

7. Daniel J. Fernandez and John D. Fernandez, "Agile Project Management: Agilism versus Traditional Approaches," Journal of Computer Information Systems 49, no. 2 (2008): 15.

8. Association for Project Management, "What Is Agile Project Management?" available online at https: / / www.apm.org.uk/resources/find-a-resource/agile-project-management/ [accessed 3 June 2018].

9. Kent Beck et al., Manifesto for Agile Software Development (2001), available online at http:/ / agilemanifesto.org/ [accessed 14 June 2018].

10. Edivandro C. Conforto, Fabien Salum, Daniel C. Amaral, Sérgio Luis da Silva, and Luís Fernando Magnanini de Almeida. "Can Agile Project Management Be Adopted by Industries Other Than Software Development?” Project Management Journal 45, no. 3 (June/July 2014): 21-34. 
between agile methods and archival project management. The body of the paper begins with a discussion of criteria commonly used to measure project success and goes on to examine some agile factors that have been quantitatively correlated with project success. Explanations of the strongest success factors are then followed by examples of how selected factors translate to archival work. By examining agile success factors in the context of America's Great Gamble, library and archives professionals might gain a practical understanding of agile theory and consider how agile factors can be adopted to support project success at their own institutions.

\section{Research Methodology}

The objective of this paper is to examine archival processing holistically, specifically from a project management standpoint, and to explore the potential application of agile methodologies to archival processing project management. This objective is achieved by studying UNLV's completed grant project in the context of available literature.

The UNLV project team performed qualitative and quantitative analysis of America's Great Gamble. Quantitative data was captured throughout the project. At the close of the project, qualitative information was obtained via open-ended questions in a group discussion. The team identified factors that contributed to the project's success and also provided ideas about how to improve future projects.

The authors conducted a literature review of archival management, archival processing projects, and project management across the libraries and archives profession. They found no literature that discussed an archival processing project's implementation holistically or provided information on its overall management. The authors viewed this gap in the literature as significant because they identified project management as the overarching factor that tied together the other components of success during their project.

The authors then expanded their literature review to include project management methods outside libraries and archives. They found that the management philosophy and technical processes implemented during America's Great Gamble closely paralleled the core values and methodologies of agile project management. They examined findings in empirical studies and case studies to learn how agile success factors translate to an archival project setting.

\section{Literature Review}

The literature includes some "how to" books that can serve as project management primers for librarians and archivists, and several studies about managing projects in libraries. However, there is a gap in the literature concerning examples of how project 
management has been implemented in special collections and archives. ${ }^{11}$ Therefore, the literature review examines two bodies of work: 1) literature on project management in libraries and archives; and 2) case studies on archival processing projects.

\section{Literature on Project Management in Libraries and Archives}

Entire books have been written on project management theory for libraries and archives, including Barbara Allan's Project Management: Tools and Techniques for Today's ILS Professional (2004), Julie Carpenter's Project Management in Libraries, Archives and Museums: Working with Government and Other External Partners (2011), and Margot Note's Project Management for Information Professionals (2016). All three argue that project management is an important skill for information professionals. ${ }^{12}$ Note's work recognizes that project management is not taught in depth or with frequency in most U.S. library school graduate programs. ${ }^{13}$ Likewise, articles by Massis and by Winston and Hoffman recognize the gap in project management education and resources for emerging librarians. ${ }^{14}$ Of the literature reviewed, Note's work is the only one that offers a comprehensive summary of project management theories as well as practical suggestions that are applicable in the field of archives. ${ }^{15}$

In describing the practical application of project management techniques, the books and articles under review generally do not specify the project management principles they followed, but it is evident that most applied traditional methods. For example, both Allan and Horwath discuss distinct project phases that are derived from traditional linear project management methods, and Zhang and Bishop describe "using a top-down planning method" and traditional Gantt charts. ${ }^{16}$ Although the literature suggests that library project managers are largely using a traditional

11. Throughout this paper, the term "archives" is used inclusively to refer to manuscript collections and organizational records as well as the organizations that are responsible for their stewardship. See the Society of American Archivists Glossary, available online at https: / /www2.archivists.org/glossary/ terms/a/archives [accessed 16 January 2018].

12. Allan, Project Management; Margot Note, Project Management for Information Professionals (Waltham, Mass.: Chandos Publishing, an imprint of Elsevier, 2015); Pam Hackbart-Dean and Elizabeth Slomba, How to Manage Processing in Archives and Special Collections (Chicago, Ill.: ALA Editions, 2013). HackbartDean and Slomba's guide explores how to develop effective processing programs that align with institutional goals. While the authors do not directly engage with project management theory and practice, their how-to guide emphasizes big-picture planning and regular reassessment of processing procedures.

13. Note, Project Management for Information Professionals, xiii-xiv.

14. Bruce E. Massis, "Project Management in the Library," New Library World 111, no. 11/12 (2010): 526-29; Mark D. Winston and Tara Hoffman, "Project Management in Libraries," Journal of Library Administration 42, no. 1 (2005): 51-61. Workshops on project management are offered by organizations such as the California Historical Records Advisory Board and the Society of American Archivists.

15. Carpenter focuses on UK government-funded projects. Allan's book is light on theory, but it presents brief examples of library project scenarios to illustrate various points.

16. Allan, Project Management; Jenn Anne Horwath, "How Do We Manage? Project Management in Libraries: An Investigation," Partnership: The Canadian Journal of Library and Information Practice and Research 7, no. 1 (2012); Ying Zhang and Corinne Bishop, "Project-Management Tools for Libraries: A Planning and Implementation Model Using Microsoft Project 2000," Information Technology and Libraries 24, no. 3 (2005): 148. 
framework, some of them exhibit agile tendencies. For instance, although she does not use the term "agile," Allan's notions align with agile principles, particularly her belief that collaborative participatory teams achieve more than hierarchically organized teams and her recognition that projects often require flexibility. ${ }^{17}$ While Allan and others may lean toward agile methods, in-depth discussion of agile practices in libraries is primarily limited to digital projects. ${ }^{18}$ This is not surprising-digital initiatives in libraries, archives, special collections, and digital humanities are supported by web development, making agile methods a natural fit for them.

In the library and archives literature reviewed for this study, Note's book is the only work that includes project management in the context of archival programs as well as libraries and museums. It is also the only work to make more than a passing reference to agile project management. In her overview of project management strategies, Note briefly summarizes agile project management. ${ }^{19}$ Although not specifically identified as "agile" in the text, Note's conception of project management includes agile principles throughout. A case in point is how she describes planning not as a discrete phase in a project, but as a dynamic, iterative, collaborative process that includes reevaluation throughout the course of the project. ${ }^{20}$ Likewise, though not explicit, it is evident that agile principles are compatible with the extensible archival processing project plans and strategies described by Santamaria throughout his book, Extensible Processing for Archives. Santamaria acknowledges using an "approach similar to that of agile software development," conducting work in "productive bursts." 21 Note and Santamaria recognize agile methods as applicable to archival work, but neither of them provides examples of how agile principles have been or might be implemented. With the exception of digital projects, the authors of this paper did not find substantial discussion of project management implementation in the context of special collections and archives. ${ }^{22}$

17. Allan, Project Management, 4-5, 9.

18. Examples include: H. Frank Cervone, "Understanding Agile Project Management Methods Using Scrum," OCLC Systems \& Services: International Digital Library Perspectives 27, no. 1 (2011); Michael Dulock and Holley Long, "Digital Collections Are a Sprint, Not a Marathon: Adapting Scrum Project Management Techniques to Library Digital Initiatives," Information Technology and Libraries 34, no. 4 (2015); Brett D. Currier, Rafia Mirza, and Jeff Downing, "They Think All of This Is New: Leveraging Librarians' Project Management Skills for the Digital Humanities," College \& Undergraduate Libraries 24, no. 2 / 4 (2017): 270-89.

19. Note, Project Management for Information Professionals, 12-13.

20. Ibid., 73-75.

21. Santamaria, Extensible Processing for Archives and Special Collections, 178.

22. Case studies about projects in special collections and archives environments reviewed for this paper primarily focus on discrete aspects of projects rather than holistically examining projects. Project management, if discussed at all, was brief. Peter Burnhill and Fred Guy, "Piloting an E-Journals Preservation Registry Service (PEPRS)," Part of the Special Issue, NASIG 2009: Riding the Rapids through a Mountain of Change 58, no. 1-4 (June 1, 2010): 117-26; Kathryn Hujda, Caitlin Marineau, and Amanda Wick, "Maximum Product, Even Less Process: Increasing Efficiencies in Archival Processing Using ArchivesSpace," Journal of Archival Organization 13, no. 3 / 4 (July 2016): 100-13; Cory Nimer and J. Gordon Daines III, "What Do You Mean It Doesn't Make Sense? Redesigning Finding Aids from the User's Perspective," Journal of Archival Organization 6, no. 4 (Oct. 2008): 216-32. While no substantial text is 


\section{Case Studies on Archival Processing Projects}

Finding no case studies that explicitly discuss project management for archives, the authors of this paper reviewed archival literature for some of the key components of project management, such as the management of time, cost, people, and processes. The literature demonstrates how archival metrics are used to plan the duration and cost of processing, how team processing supports efficiency, and how efficient processing techniques promote the flexibility needed to adapt to change.

Both traditional and agile project management methodologies place importance on monitoring progress. Much of the literature on archival management, particularly in reference to productivity and efficiency, includes discussion about tracking time and assessing processing rates. ${ }^{23}$ Given how variables can dramatically impact processing rates, some authors argue that it is futile to attempt to create a standard measure for the number of hours required to process material. ${ }^{24}$ The Guidelines for Efficient Archival Processing in the University of California Libraries address some of the processing rate variables in a decision-making matrix that charts five levels of effort and control in the areas of arrangement, description, preservation, and appraisal. ${ }^{25} \mathrm{~A}$ companion matrix, which corresponds with the five levels of effort/control, provides benchmarks for processing rates that account for variables such as the condition and complexity of the materials. ${ }^{26}$ The literature suggests that, although processing rates are not uniform from one institution to another, or even from one project to another, estimating rates is possible and important. Although variables introduce undeniable challenges to establishing benchmarks for processing rates, the prevailing literature advocates for capturing processing metrics. Case studies by Abraham et al., W. N. Davis Jr., and Emily Novak-Gustainis assert that processing metrics are valuable for forecasting project duration and cost. ${ }^{27}$ As Santamaria points out, "Without metrics, planning processing projects and communicating expectations for processing work become

available, slides from a panel at Archives ${ }^{\star}$ Records 2016 demonstrate the applicability of agile methods to archival processing projects. "Into the Scrum: Applying Agile Project Management to Archival Processing” (Archives ${ }^{\star}$ Records 2016, Atlanta, Georgia, July 31-August 6, 2016).

23. See, for example, Terry Abraham, Stephen Balzarini, and Anne Frantilla, "What Is Backlog Is Prologue: A Measurement of Archival Processing," The American Archivist 48, no. 1 (Winter 1985):31-44; Crowe and Spilman, "MPLP @ 5: More Access, Less Backlog?” Journal of Archival Organization 8 (2):110-33; and Emily R. Novak-Gustainis, "Processing Workflow Analysis for Special Collections: The Center for the History of Medicine, Francis A. Countway Library of Medicine as Case Study," RBM: A Journal of Rare Books, Manuscripts, and Cultural Heritage 13, no. 2 (2012): 113-28.

24. See Carl Van Ness, "Much Ado about Paper Clips: 'More Product, Less Process' and the Modern Manuscript Repository," Society of American Archivists 73, no. 1 (Spring/Summer 2010): 129-45.

25. University of California Libraries, Guidelines for Efficient Archival Processing in the University of California Libraries (Sept. 18, 2012): 15-16.

26. Ibid., 23.

27. Abraham et al., "What Is Backlog Is Prologue"; W.N. Davis Jr., "Budgeting for Archival Processing," American Archivist 43, no. 2 (Spring 1980): 209-11; and Novak-Gustainis, "Processing Workflow Analysis for Special Collections." 
nearly impossible." ${ }^{28}$ This is particularly true for grant-funded project proposals, which often require an outline of processing methods, timelines, work plans, and division of labor.

The division of labor and composition of a processing team strongly influence the outcomes of a project. Case studies in archival literature discuss the division of labor and composition of successful teams. ${ }^{29}$ Some literature reflects traditional project team management, wherein professional archivists perform arrangement and description, and delegate only the most routine tasks to paraprofessionals, students, and volunteers. ${ }^{30}$ Other literature describes a more collaborative, less hierarchical approach — how student assistants inventory, arrange, and describe materials under the supervision of a professional archivist. ${ }^{31}$ One nonhierarchical team approach is described by Richard W. Hite and Daniel J. Linke, who explain that their "method of team processing is egalitarian, with emphasis on important and necessary tasks being performed by both members of the team, as opposed to delegating the more menial tasks to lower ranked and lower-paid individuals." ${ }^{32}$ Hite and Linke's approach integrates coworkers rather than separating people by level of education or professional experience. They also state that a key to their success "was a flexible division of labor." ${ }^{33}$

In addition to recognizing the importance of a flexible division of labor in project success, the literature also discusses the value of flexible processing techniques such as efficient processing. ${ }^{34}$ Efficient processing anticipates iterative work on collections,

28. Santamaria, Extensible Processing for Archives and Special Collections, 113.

29. Christopher Honts, Matthew Prewett, John Rahael, and Michael Grossenbacher, "The Importance of Team Processes for Different Team Types," Team Performance Management: An International Journal 18, no. 5 / 6 (2012): 312-27; Helen Slotkin and Karen Lynch, "An Analysis of Processing Procedures: The Adaptable Approach," American Archivist 45, no. 2 (Spring 1982): 156.

30. Slotkin and Lynch, "An Analysis of Processing Procedures"; Paul Eriksen and Robert Shuster, "Beneficial Shocks: The Place of Processing-Cost Analysis in Archival Administration," American Archivist 58 (Winter 1995): 48; Eriksen and Shuster noted that, at the Graham Center, students and volunteers may assist with work, but "professional staff do the majority of the processing"; Van Ness, "Much Ado About Paper Clips," 138-39; Van Ness believes that, "at most institutions, people at the bottom of the archival workforce hierarchy perform the labor-intensive preservation tasks."

31. See discussion of students processing collections under the direction of archivists in Abraham et al., "What Is Backlog Is Prologue," 35; Crowe and Spilman, "MPLP@ 5," 111, 115: Crowe and Spilman explain that students perform minimal processing with little supervision at University of Minnesota and found that 75 percent of repositories employ students and/or volunteers. See also the discussion of student work performed under the direction of professionals in Emily Gainer and Michelle Mascaro, "Faster Digital Output: Using Student Workers to Create Metadata for a Grant Funded Project,"

Provenance, Journal of the Society of Georgia Archivists 30, no. 1 (2012): 12; Michael Strom, "Texas-Sized Progress: Applying Minimum-Standards Processing Guidelines to the Jim Wright Papers," Archives Issues 29, no. 2 (2005): 110; Strom describes a scenario in which student assistants performed a great deal of processing with little intervention from the archivist.

32. Richard W. Hite and Daniel J. Linke, “Teaming Up with Technology: Team Processing," Midwestern Archivist 15, no. 2 (1990): 91.

33. Ibid., 96.

34. The terms "efficient processing," "iterative processing," and "extensible processing" are variations on the same theme and are used interchangeably in this paper. 
requiring plans and methods that can grow and change to meet shifting priorities. While not universally practiced, selecting an appropriate "level" of processing for materials has been acknowledged in archival literature as acceptable practice for more than three decades and has been widely adopted..$^{35}$ Although efficient processing undeniably supports effective archival management, it is only one component of successful archival project management. An empirical study by Prom shows a "lack of a strong correlation" between efficient processing and increased productivity or collection access. ${ }^{36}$ Prom suggests there are many factors influencing processing productivity —including the overall management of the archival project or program.

The archival processing studies reviewed here are founded on sound theories and communicate procedures of value to the archival community, but they are limited to specific aspects of each project. Although it is valuable to examine the details of arrangement and description, it is far more valuable when those details are considered within the context of the entire enterprise. This study considers the larger context of an archival project, America's Great Gamble.

\section{America's Great Gamble Project Background}

The UNLV University Libraries supports teaching, learning, research, and creative endeavors at one of the nation's fastest-growing universities. UNLV is an urban research institute of approximately 30,000 students and more than 3,000 faculty and staff. ${ }^{37}$ In both 2017 and 2018, UNLV received top ranking as the most diverse undergraduate campus in the nation, and its William F. Harrah College of Hospitality was ranked number one in the world for education in hospitality and leisure management. ${ }^{38}$

\footnotetext{
35. Data suggest that 75 percent of respondents employed efficient processing via an "MPLP-style approach," Jackie M. Dooley and Katherine Luce, Taking Our Pulse: The OCLC Research Survey of Special Collections and Archives (Dublin, Ohio: OCLC Research, 2010), 49. See also the five premises outlined in Slotkin and Lynch, "An Analysis of Processing Procedures," 155-163; the processing continuum in Megan Floyd Desnoyers, "When Is a Collection Processed?" Midwestern Archivist 7, no. 1 (1982): 5-23; Mark A. Greene and Dennis Meissner, "More Product, Less Process: Revamping Traditional Archival Processing," American Archivist 68, no. 2 (2005); Crowe and Spilman, "MPLP @ 5,"110-33; Adrienne R. Harling, "MPLP as Intentional, Not Necessarily Minimal, Processing: The Rudolf W. Becking Collection at Humboldt State University," American Archivist 77, no. 2 (2013): 489-98; Rachel Anchor, "More Product, Less Process': Method, Madness or Practice?” Archives \& Records 34, no. 2 (2013): 156-74; and Santamaria, Extensible Processing for Archives and Special Collections.

36. Prom, "Optimum Access?" 158.

37. "About UNLV. Facts and Stats," available online at https://www.unlv.edu/about/ facts-stats [accessed 2 October 2018].

38. “U.S. News \& World Report: UNLV Most Diverse Campus in the Nation,” University of Nevada, Las Vegas (Sept. 12, 2017), available online at www.unlv.edu/news/release/us-news-world-report-unlvmost-diverse-campus-nation [accessed 2 October 2018]; "Hospitality \& Leisure Management," Top Universities, available online at https://www.topuniversities.com/university-rankings/university-subjectrankings/2017/hospitality-leisure-management and https:/ / www.topuniversities.com/university-rankings/ university-subject-rankings/2018/hospitality-leisure-management [accessed 2 October 2018].
} 
The Libraries has a strong community mission and actively documents the region's history through the Special Collections and Archives (SCA) Division and its two research centers: the Center for Gaming Research and the Oral History Research Center. The Libraries' holdings include rare books and archival collections that "document the history and statistical basis of games and gambling; the economics and regulation of the gaming industry; the psychological, social, and political effects of gambling; and the history of specific hotels and casinos throughout the world." ${ }^{39}$ Given the university's reputation as a worldwide leader of education in hospitality, leisure management, and the gaming industry, it is an organization-wide priority for UNLV to provide access to archival collections that support research in those areas. A preliminary review of UNLV's archival holdings confirmed the existence of several inaccessible collections on gambling and casinos; however, the SCA Technical Services Department did not have the capacity to undertake these large-scale projects. ${ }^{40} \mathrm{UNLV}$ therefore applied for a grant from the National Historical Publications and Records Commission (NHPRC) to process approximately 400 linear feet of archival materials that support research on the growth of the gaming industry. ${ }^{41}$

\section{Project Summary}

The University Libraries was awarded $\$ 129,600$ from the NHPRC to preserve and make accessible four archival collections that document the history of gambling in the United States. This eighteen-month project, America's Great Gamble: A Project to Promote the Discovery of Sources about the Expansion of Legalized Gambling across the United States, improved the discoverability and accessibility of collections that provide significant evidence of the rapid expansion of casinos, Native American gaming, ${ }^{42}$ and legalized gambling in the United States from the 1950s through the early 2000s. Materials in these collections support research and analysis of top-

39. "Gaming," Special Collections \& Archives, University Libraries, available online at https://www. library.unlv.edu/speccol/collecting_strengths/gaming [accessed 4 October 2018].

40. UNLV has only one full-time archival processor (a paraprofessional). Processing is only 50 percent of her duties.

41. Details about the NHPRC project can be found online: Special Collections \& Archives, University Libraries, "America’s Great Gamble: NHPRC Grant-Funded Archival Processing Project," available online at https:/ / sites.google.com/unlv.edu/americas-great-gamble-nhprc/home [accessed 4 October 2018].

42. The project team purposefully chose the term "Native American gaming" for a few reasons. First, the Library of Congress Subject Heading for this topic, "Gambling on Indian Reservations," is inaccurate in this context due to the presence of off-reservation casinos owned by Native American nations. Further, by focusing on the act of gambling, this subject heading does not address ownership and management of casinos by Native American peoples. Finally, we chose to use the imperfect term "Native American" because it covers a broad range of Indigenous peoples in North America who have embraced gaming as a means to improve their economic conditions both on and off reservations. Although commonly used in the casino industry, the terms "Tribal" and "Indian" were avoided as they are used less frequently in current anthropological, historical, and sociological scholarship. These descriptive choices reflect the project team's commitment to archival reconciliation with Indigenous peoples and the profession's commitment to creating culturally competent archival descriptions. 
ics such as the development of gaming enterprises by Native American nations; municipal, state, and federal gambling law and regulation; casino management and operational control; compulsive gambling; and other socioeconomic topics related to gambling.

The project team was composed of a principal investigator, project manager, curator, publicity manager, MARC cataloger, and a subteam of archival processors. The project manager and principal investigator planned the project and provided ongoing support to the processing team. Other UNLV Libraries staff contributed subject knowledge, conservation support, and budget management to the project. ${ }^{43}$ The project manager strategically recruited archival processing team members that had technical abilities, subject expertise, and collaborative attitudes. The processing team included four members: lead project archivist, project archivist, graduate student processing assistant, and undergraduate student processing assistant.

Undertaking the America's Great Gamble project not only offered UNLV SCA the opportunity to process significant legacy collections and make them accessible to researchers, it also allowed the SCA Technical Services Department staff to pilot a project management approach that was new for them. The project manager was a novice with little formal project management training. She set up the project infrastructure based on basic project management concepts and developed the rest of the processes gradually in collaboration with the archival processing team. Only after the project was completed did the team connect agile project management practices with America's Great Gamble. During their postproject assessment, the team overlaid a framework of agile practices onto the completed project and began to appreciate how the environment, technical processes, and team fit together to support project success.

\section{Evaluating Project Success}

Regardless of the industry or management style, three criteria (sometimes called the triple constraint) are universally used to measure project success:

- Time: was the end result/product completed/delivered on schedule?

- Cost: was the project completed within the budget?

- Quality: is the end product effective? Did it meet the scope, quality, and predefined stakeholder requirements?

Project management literature across disciplines consistently reflects these three

43. Supporting UNLV Libraries staff who were not part of the grant project included an accountant, conservator, and additional curators. 
traditional criteria. Some authors, however, suggest additional criteria intended to create a more holistic definition of project success. ${ }^{44}$ Some of the additional attributes of success found in the literature include the following criteria:

- Project team has learned from the experience ${ }^{45}$

- Project team is satisfied with results/ product $^{46}$

- Improved business processes ${ }^{47}$

- Improved services ${ }^{48}$

- Organizational improvement ${ }^{49}$

- Project contributes to success of wider business goals ${ }^{50}$

- Project is perceived to have high congruence with the organization's strategic goals $^{51}$

The authors of this paper agree that, in addition to efficiency (time and cost) and effectiveness (quality), the success of a project should be measured not only at the project level but also at the organizational level. To be considered truly successful, a project must be aligned with the strategic goals of the organization and contribute to improving the organization in some way (processes, services, development of staff skills, and other factors).

\section{Translating Agile Success Factors to Archival Projects}

In their study on agile methods, Conforto et al. define agile project management as "an approach based on a set of principles, whose goal is to render the process of project management simpler, more flexible and iterative to achieve better performance (cost, time and quality), with less management effort and higher levels of innovation and added value for the customer." ${ }^{52}$ In theory, these agile principles and goals could easily align with a variety of projects across different industries and disciplines, including libraries and archives. America's Great Gamble illustrates how principles and practices that are agile can align well with efficient processing and have the potential to contribute to the success of archival projects.

\footnotetext{
44. See, for example, Pedro Serrador and Jeffrey K. Pinto, "Does Agile Work? A Quantitative Analysis of Agile Project Success," International Journal of Project Management 33 (2015): 1043-44; Note, Project Management for Information Professionals, 33-34; Subhas Chandra Misra, Vinod Kumar, and Uma Kumar, "Identifying Some Important Success Factors in Adopting Agile Software Development Practices," Journal of Systems \& Software 82, no. 11 (2009): 1871.

45. Horwath, "How Do We Manage?" 28.

46. Serrador and Pinto, "Does Agile Work?" 1046.

47. Misra, Kumar, and Kumar, "Identifying Some Important Success Factors," 1871.

48. Note, Project Management for Information Professionals, 33.

49. Ibid, 34 .

50. Serrador and Pinto, "Does Agile Work?" 1043.

51. Ibid., 1043.

52. Conforto et al., "Can Agile Project Management Be Adopted by Industries Other Than Software Development?" 22.
} 
Studies on agile project management agree that agile principles and practices contribute to project success. For example, Serrador and Pinto's large-scale quantitative analysis of 1,002 projects across various industries and countries shows that the degree to which a project employs agile methods "does have a statistically significant impact on all three dimensions of project success, as judged by efficiency [time and cost], stakeholder satisfaction, and perception of overall project performance [quality]." ${ }^{33}$ There is also consensus that agile factors, such as organizational conditions, technical execution, staff skills, and agile processes, greatly contribute to project success. However, individual studies and empirical data analyses differ somewhat in their conclusions regarding which factors have the strongest influence on project success.

After analyzing survey responses for 109 projects from 25 countries, Tsun Chow and Dac-Buu Cao conclude that the only critical success factors are "(a) a correct delivery strategy, (b) a proper practice of Agile software engineering techniques, and (c) a high-caliber team. Three other factors that could be critical to certain success dimensions are found to be (a) a good Agile project management process, (b) an Agile-friendly team environment, and (c) a strong customer involvement." ${ }_{54}$ On the other hand, Misra, Kumar, and Kumar's analysis of data from 174 survey responses reveals nine factors that have a statistically significant influence on success: customer satisfaction, customer collaboration, customer commitment, decision time, corporate culture, personal characteristics of staff, societal culture, and training and learning. ${ }^{55}$ The top success factors in Misra, Kumar, and Kumar's findings are more specific but are largely compatible with the findings of Chow and Cao. Other studies, such as those of Conforto et al. and Sanjiv Augustine et al., discuss how agile factors support success but do not rank their relative impact. ${ }^{56}$

Many factors identified as strong contributors to project success are relevant to archival processing projects. The factors are commonly broken into five main categories, referred to as "dimensions": Project, Organizational, Technical, People, and Process. Within those dimensions, there are up to forty-eight agile success factors listed. Chow and Cao consolidate related factors, reducing the forty-eight terms to twelve broader terms, only six of which demonstrate significant relationships to project success. The remainder of this paper concentrates on the primary success factors shortlisted by Chow and Cao (including lesser factors when relevant)

\footnotetext{
53. Serrador and Pinto, "Does Agile Work?" 1049.

54. Tsun Chow and Dac-Buu Cao, "A Survey Study of Critical Success Factors in Agile Software Projects," Journal of Systems \& Software 18, no. 6 (2008): 969.

55. Misra, Kumar, and Kumar, "Identifying Some Important Success Factors," 1878.

56. Conforto et al., "Can Agile Project Management Be Adopted by Industries Other Than Software Development?"; Sanjiv Augustine, Bob Payne, Fred Sencindiver, and Susan Woodcock, "Agile Project Management: Steering From the Edges," Communications of the ACM 48, no. 12 (Dec. 2005).
} 
and discusses the factors in the context of archival processing. ${ }^{57}$ To translate the unfamiliar concepts from another discipline into archival practice, each discussion includes concrete examples of how selected factors contributed to the success of America's Great Gamble.

\section{Project Factors}

Although the literature anecdotally suggests that agile practices are enabled by factors related to a project's nature, Chow and Cao found that factors in the Project dimension "failed to make any impact at all" on project success. ${ }^{58}$ Given that there is no proven correlation between this dimension and project success, no further discussion of Project Factors is warranted here.

\section{Organizational Factors}

The literature consistently suggests that an agile-friendly organizational culture and structure facilitate the implementation of agile practices, but the separate empirical analyses led by Chow and by Misra show that an agile-style team environment is the only organizational factor found to have significant impact on project success. ${ }^{59}$ Organizational factors that encourage agile practices include the following:

- Organizational structure: not too bureaucratic, allowing for decentralized decision making

- Organizational culture: supports a progressive, cooperative, innovative spirit

- Executive support

- Rapid stakeholder response time

- Culture of performance measuring ${ }^{60}$

- Agile-style team environment

- Co-location of entire team (working together in one room)

It is unlikely that a project manager will have the power to significantly influence an established organizational structure or culture; but, within the project environment, archival project managers can model a culture of cooperation, decentralized decision making, and performance measuring. Managers can assemble a well-rounded archival processing team, create an agile-style team environment, and advocate for work space that brings team members together in one room. An agile-style workspace is designed to enable collaboration, mentoring, and frequent

57. The factors discussed here are selected, not comprehensive. Factors that appear in more than one dimension in the literature (such as co-located work space) are listed in only one dimension in this paper. For fuller lists of project success factors, see Conforto et al., "Can Agile Project Management Be Adopted by Industries Other Than Software Development?" 25; Chow and Cao, "A Survey Study of Critical Success Factors," 963.

58. Chow and Cao, "A Survey Study of Critical Success Factors," 967.

59. Ibid., 969.

60. Performance measuring is addressed in the Process dimension below. 
face-to-face communication among team members. In addition to facilitating teamwork, the physical openness of an agile-style environment is conducive to arranging and rehousing large collections.

\section{Example of an Agile-style Team Environment}

The workspace for America's Great Gamble was intentionally designed to support teamwork and concurrent processing of multiple collections. The four-person processing team worked together in an open space with shared desktop and laptop computers (no cubicles). Having the computers within the open processing space enabled the team to create collection descriptions and project documentation while they physically processed materials at adjacent tables. Thanks to eight large movable tables on casters, the space was reconfigured regularly during the project to accommodate changing physical demands such as surveying, arrangement, boxing, and foldering. Stationing the team together supported team-building activities, brainstorming (facilitated by a large whiteboard), and spontaneous problemsolving. Their co-location facilitated immediate and collaborative decision making when archival processing questions arose, allowing work to proceed without delay.

\section{Technical Factors}

In their evaluation of success factors, Chow and Cao rank "a proper practice of agile software engineering techniques" very highly. ${ }^{61}$ Since agile studies generally focus on software development, the factors in the technical dimension relate to the writing and testing of computer code and the design, engineering, and release of software. Fundamentally, however, these factors refer to the technical execution of the project, and some of them translate well to archival processing. Factors that are applicable to archival projects include:

- Well-defined coding standards upfront

- $\quad$ Pursuing simple design

- Right amount of documentation

- Delivering most important features first

- Appropriate technical training for team ${ }^{62}$

Practicing sound archival processing techniques contributes to the quality of the end product, ensuring long-term preservation of and access to collections. The core technical actions in archival processing are arrangement, description, and conservation, all of which are governed by well-defined professional standards and best practices. "Pursuing simple design" is comparable to retaining original order when

61. Chow and Cao, "A Survey Study of Critical Success Factors," 969.

62. Technical factors are taken directly from Chow and Cao, "A Survey Study of Critical Success Factors," 963. 
possible and performing only as much arrangement and description as needed to provide access to collections (efficient processing). Creating the "right amount of documentation" refers to documenting the code, which means documenting work that has been done. For an archival project, this means focusing energy primarily on archival processing and documenting project activities selectively. For a largescale project, systematically documenting the major decisions and progress of the project enables the team and organization to learn from the experience. Ongoing documentation also provides reliable and ready content for required grant project reports. "Delivering the most important features first" maps to extensible processing, which prioritizes processing the richest content and/or least accessible material first and returning to enhance arrangement and description of other parts of the collection if time allows. Finally, appropriately training a team includes providing them with a solid theoretical foundation, teaching them practical archival processing and conservation techniques, and training them in the technologies that support processing.

\section{Example of Technical Factors}

The technical standards for America's Great Gamble were determined prior to the grant period, documented in the grant proposal, and adhered to throughout the project. The project was conceived and executed within a framework of efficient and extensible processing, ${ }^{63}$ and its progress was measured using the processing rates published in the Guidelines for Efficient Archival Processing in the University of California Libraries. ${ }^{64}$ The team followed these technical standards: Describing Archives: A Content Standard for arrangement and finding aid creation; Resource Description and Access for creation of names and subject headings in finding aids and MARC records; and the Northeast Document Conservation Center for rehousing materials and performing conservation treatment such as humidification, flattening, and encapsulation. ${ }^{65}$

The amount of documentation was right for the project. Processing metrics, plans, and collaborative meeting notes were updated and documented in real time. Processing metrics were recorded to gauge if processing techniques needed to be adapted to meet deadlines. This documentation was the bedrock of the quarterly progress reports submitted to the NHPRC. ${ }^{66}$

63. Greene and Meissner, "More Product, Less Process," 208-63; Santamaria, Extensible Processing for Archives and Special Collections.

64. University of California Libraries, "Guidelines for Efficient Archival Processing."

65. The Society of American Archivists, Describing Archives: A Content Standard, Second Edition, Chicago: 2013; Resource Description and Access, available online at https://www.loc.gov/aba/rda/ [accessed 15 July 2018]; Northeast Document Conservation Center, available online at https://www.nedcc.org/ [accessed 15 July 2018].

66. A summary report on the metrics for America's Great Gamble can be found on the "America's Great Gamble” project website, available online at https:/ / sites.google.com/unlv.edu/americas-great-gamblenhprc/processing-overview [accessed 4 October 2018]. 


\section{People Factors}

Quantitative analyses and individual studies both confirm that people factors are as critical to project success as technical factors. ${ }^{67}$ Although the people dimension includes factors related to training, mentoring, technical skills, interpersonal skills, and behaviors of team members and managers, the Chow and Cao study identified a "high-caliber team" as the only critical factor in this category. These findings dovetail with the Misra, Kumar, and Kumar study, which found a significant correlation between people and project success, particularly the personal characteristics and technical skills of the team members. Taking both studies into account, the attributes of a high-caliber team include:

- Team with experience, expertise, and diverse competencies

- Team with the information and autonomy to make decisions

- Team members that are highly motivated and invested in the project

- Team with appropriate technical training

- Informal training through mentoring and tacit transfer of knowledge

- Coherent, self-organizing team

- Personal characteristics of team members: honest, collaborative, sense of responsibility, eager to learn from and share information with others

- Manager with a light touch and adaptive management style

- Strong stakeholder involvement

- Good customer relationships

Agility is enabled by a multidisciplinary team that has the information, experience, and motivation to manage themselves and direct their own activities. An agile archival processing team might adopt any number of archival processing strategies. Agile practices can only be applied to archival processing projects when the team (as a whole) possesses technical abilities and subject expertise that enable them to understand the research value of collection materials and make informed decisions about priorities for arrangement, description, and conservation. The team must have at least one member with strong archival processing skills who can teach and mentor less experienced teammates. Agile practices demand a manager that guides the team, removes barriers that impede progress, and adapts her management style to the team and the project. Given a skilled and motivated team, an agile manager can have a light touch, allowing the team to determine individual roles and how they will work together to achieve the project's objectives. A fair division of labor, mutual respect, open communication, and shared goals foster collaboration that can result in a cohesive and productive team. When a degree of decision making

67. See Conforto et al., "Can Agile Project Management Be Adopted by Industries Other Than Software Development?"; Chow and Cao, "A Survey Study of Critical Success Factors"; Misra, Kumar, and Kumar, "Identifying Some Important Success Factors"; Serrador and Pinto, "Does Agile Work?"; Augustine et al., "Agile Project Management." 
and responsibility for the project's success rests in the hands of all team members, each of them becomes more motivated and invested in the project.

In addition to healthy working relationships among team members, good relationships between the team and the customers and stakeholders also support success. In an archival project, this may entail ongoing communications with the donors or creators of the collections, the end users of the collections, and/or the funding agency.

\section{Example of High-Caliber Agile Team Practices}

The America's Great Gamble project team possessed complementary competencies. Their combined subject expertise, skills, collegiality, and agility were key to project success. The larger project team included archivists, an outreach librarian, a cataloging librarian, curators, and student processing assistants. The team was also supported by nonproject personnel, namely an accountant and a book and paper conservator. Collectively, the processing team members possessed the subject expertise they needed to understand the contents of the collections and determine how best to arrange and describe them. Three of the four processing team members possessed the archival experience needed for the team to be self-organized and self-directed. The fourth team member had no archival processing experience but filled a critical gap in the subject expertise of the team. Because the team was co-located in an open work space, the team members with archival experience were able to work side by side with the subject expert and mentor him in archival processing techniques.

In addition to possessing the technical experience and subject expertise required to process the collections, the processing team members all had strong work ethicsthey were highly motivated and took responsibility for moving the project forward. The skills and characteristics of the team gave the manager the confidence to grant the team autonomy and allow them to determine how they would organize themselves. Despite differences in education, experience, and pay grades, the team divided labor equally. Responsibilities were sometimes assigned according to a team member's area of expertise, but all team members worked on intellectual efforts (such as research, planning, arrangement, description, authoring promotional material, etc.) as well as logistical tasks (such as box building, collection retrieval and storage, etc.). This egalitarian division of labor demonstrated the mutual respect that was the cornerstone of the team's collaboration. The contributions of all team members, from undergraduate assistant to project manager, were equally valued. All team members were empowered to propose process improvements and trusted to test, implement, and document proposed changes. 


\section{Example of Strong Customer Involvement and Relationships}

America's Great Gamble presented opportunities to involve collection creators, end users, and the funding agency in the project. Project staff maintained strong customer relations by communicating with the creators of the collections during the planning process and at several points during collection processing. The collection creators provided contextual background for the collection descriptions, advice on arrangement, identification of mystery photographs, and clarity on potentially restricted materials. End users (that is, scholars who conducted research in the unprocessed collections prior to and during the grant period) offered insights that informed arrangement and description.

The funding agency, the NHPRC, worked closely with the project investigator during the proposal period and was very responsive when the team requested a significant change to the performance objectives. The original grant proposal required arranging and describing three unprocessed collections totaling just over 350 linear feet. However, when project staff recalled a collection from off-site storage to find it had been overestimated by 31 linear feet, they contacted the NHPRC. Because the overall volume of the three collections was notably less than the linear footage in the approved proposal, the curator proposed the addition of a large, partially processed collection. The NHPRC worked with UNLV's principal investigator to revise the grant performance objectives to include four collections for a total of 420 linear feet. Collaborative relationships with the project customers and stakeholders improved the scope, arrangement, and description of the materials, which ultimately improved access and the user experience.

\section{Process Factors}

Process refers to how the project is planned, managed, and executed. Chow and Cao present empirical evidence that establishes the importance of process factors in project success, but they assume their audience is familiar with these processes. Conforto et al. explain the process factors clearly for an audience outside software development. Drawing from both studies, some of the basic characteristics of agile-oriented project management processes are:

- Agile-style planning

- Project plan defined at the macro level and developed by iteration

- Frequent project plan updating

- Project plan progress and updating is a shared responsibility

- Strong communication

- Easy access to information

- Frequent milestones

- Progress tracking mechanism 
Process factors are very relevant to archival processing and are discussed at length here. The discussion is broken into three sections: Agile-style Archival Planning, Communication and Access to Information, and Progress Tracking.

\section{Agile-style Archival Planning}

Archivists who create extensible processing plans, which anticipate and plan for change, will find that agile-style project planning is familiar territory. Agile-style plans expect more nuanced planning to occur incrementally during the execution of the project. In many situations, creating a project plan at the macro level for an archival project is sufficient for determining goals, scope, framework, timeline, and budget, and the team can develop details iteratively as the project matures. Some descriptions of agile methods leave the impression that project preplanning can fit entirely on a few Post-it ${ }^{\circledR}$ notes and that project participants make everything up as they go along. This is not so. Agile methods avoid rigid or overly detailed plans, but most begin with sophisticated upfront plans that are poised for change. ${ }^{68}$

For archival processing, adaptable planning occurs up front as well as throughout the project. Conducting a preliminary survey can adequately predict the scope and nature of the work to be done and the processing skills needed to complete the work. Estimating the following information can provide a starting point for planning budgets, staffing, and timelines: level of processing to be performed (minimal to highly intensive), subject expertise required to arrange and describe collection, technical expertise required (for special formats, born-digital materials, conservation, etc.), number of hours needed to process collection(s), and archival supplies needed. For multicollection projects, the team must coordinate individual processing plans under the macro project plan. During the execution of the project, the overarching project plan and collection-level processing plans should be regularly discussed and updated. This positions the team to not only accommodate unexpected challenges but also to take advantage of opportunities to implement ideas that improve productivity, processes, or the end result.

\section{Example of Agile-style Archival Planning}

The planning and execution of America's Great Gamble bore the hallmarks of agile project management. While the infrastructure and policies were solid, the project plans and procedures were intentionally fluid. The principal investigator and project manager outlined preliminary processing levels, macro-level processing timelines, and project needs in the grant proposal. Once hired, the team surveyed the collections, adapted the timeline and activities outlined in the grant proposal's project narrative, and set incremental goals based on the expectations expressed in the funding agency's award summary. Details for all components of the macro project

68. See Serrador and Pinto, "Does Agile Work?” 1042. 
plan were developed collaboratively and iteratively as the project progressed. The plan was constantly monitored and updated. The team shared responsibility for updating the plan.

An agile planning approach was essential when the fourth collection was unexpectedly added to the project. First, the team compressed the processing timelines for the other three collections to fit the additional collection into the project schedule. They then surveyed the newly added collection and focused the processing plan on the least accessible materials. Accustomed to employing iterative processing, they identified the materials most worthy of more granular processing, which they planned to perform near the end of the project if time permitted.

\section{Communication and Access to Information}

Agile-oriented project planning and execution requires strong cross-directional communication. When discussing agile project management, Sanjiv Augustine et al. explain, "For an agile team to adapt, information must be open and freeflowing...team members benefit from the power of knowledge..." ${ }^{69}$ Access to project information empowers team members as decision makers and allows them to meaningfully contribute to the project. Updating plans and progress in real time ensures that the team is basing decisions on current information. Open and ongoing dialog enables staff to identify areas of convergence in their activities which can lead to efficiencies.

\section{Example of Communication and Access to Information}

During America's Great Gamble, ongoing communication occurred formally and informally, online and in person. Daily pop-up meetings in the team's shared space allowed for spontaneous conversations and immediate action related to new ideas. During official weekly meetings, the processing team met with the project manager to assess progress and update goals. Documentation (performance objectives, grant requirements, project metrics, working documents, and various iterations of plans) was accessible to everyone involved in the project, making the process, goals, and challenges transparent.

While transparency is important, it is equally important for all members of the project team to understand that they have not only the knowledge, but also the power, to question and change project plans. Early in the project, the undergraduate processing assistant recognized a way to improve a plan, but she did not believe she had the authority to question the plan. She followed the existing plan to the letter until it significantly inhibited her progress, at which time she suggested the plan she had devised. Although she felt respected by the team from the onset, she did not truly believe she

69. Augustine et al., "Agile Project Management," 86-87. 
had an equal voice in the project until her plan was implemented. It took time for some team members to develop a level of comfort in communicating their ideas.

The communication among processing team members and the project manager was frequent and effective. However, in retrospect, the processing team felt they would have benefitted from more face-to-face communication with other project team members, particularly the principal investigator and the curator. These project team members were responsive to e-mails and requests to physically review collection materials with the processing team, but the processors felt slightly disconnected from them. The processors suggested that management of future projects include regularly scheduled meetings for all project participants to share ideas and project updates. Meetings with the larger team boosted the morale of the processing team by affirming that their work was valuable to the organization.

To support communication, the UNLV project team considered tools such as Basecamp and Trello, but they selected the Google suite of tools as their primary means of managing project information and tasks. Compared to formal project management tools, Google applications have almost no learning curve, and data can easily be shared online or exported for assessment. Unlike files shared on a local network, Google files can be accessed from anywhere and updated simultaneously by multiple users. The project team shared information with one another and with project supporters (the conservator who managed archival supplies and the accountant who managed the budget) via Google Docs and Sheets. New Google Sites empowered the project team to publish a simple stand-alone website about America's Grant Gamble that summarizes the work completed during the project. ${ }^{70}$

\section{Progress Tracking}

As with most types of projects, agile-oriented projects have hard deadlines and employ metrics to determine feasibility, monitor progress, evaluate performance, and manage schedules and budgets. ${ }^{71}$ In an agile archival processing environment, ongoing metrics support overall project management by indicating actual progress toward goals. The pace of progress, including detailed information indicating how much time is devoted to specific activities, enables the team to identify processes that are either running smoothly or failing and adjust activities accordingly. Charting progress at the individual level indicates areas where team members are most effective. By assessing metrics early and often, timelines projected for processing

70. "America’s Great Gamble” project website, available online at https://sites.google.com/unlv.edu/ americas-great-gamble-nhprc/home [accessed 4 October 2018].

71. For a thorough introduction to agile software development metrics tools and methods, see Will Hayes, Suzanne Miller, Mary A. Lapham, Eileen Wrubel, and Timothy Chick, Agile Metrics: Progress Monitoring of Agile Contractors, Carnegie Mellon University (Jan. 2014), available online at https: / / resources.sei.cmu.edu/asset_files/TechnicalNote/2014_004_001_77799.pdf [accessed 16 July 2018]. 
each collection can be broken into realistic, adjustable milestones defined by discrete tasks. Metrics and milestones provide an important sense of accomplishment and encouragement for the team, particularly during long-term projects.

An agile approach requires a team to continually reassess proposed processing strategies for each collection in light of overall priorities and up-to-date processing metrics. To assess processing techniques and progress, archival processors must track the time they spend on processing tasks-logistics, research, processing, planning, surveying, arrangement, foldering, creating inventories, and description - as well as the linear/cubic footage of materials processed per hour. ${ }^{72}$ However, processing metrics alone do not provide a complete picture of how time is allocated during a project. To fully inform project decisions, processors should also record time spent on all recurring or significant project responsibilities, such as administrative activities, staff meetings, training, promotional activities, and report writing. By adding a few additional data points to processing metrics, archivists can use metrics not only as a means for predicting processing rates but also as a project management tool. Data can be assessed to monitor processing efficiency, identify barriers to progress, analyze how work is assigned to different team members, demonstrate progress to stakeholders, provide guidance for the next steps, and keep the project on schedule. Ideally, staff should track their progress daily, so decisions can be based on current information. Like all project documentation, metrics must be transparent to all team members to support them in making informed decisions.

\section{Example of Progress Tracking}

The UNLV team used project metrics (including processing rates) as a project management tool. Before the project began, the project manager created separate, but uniform, metrics templates for each collection. Once the team was hired, they enhanced the template by adding new data points and color codes for multiple individuals working together on a single collection. At any time, any team member could export, filter, aggregate, and assess collection-specific data or view project progress holistically. Daily metrics enabled the team to observe and correct shortterm trends that might have become problems. For example, the lead project archivist regularly compared actual processing rates with the rates estimated in the grant proposal to calculate whether or not the project was on schedule. If rates showed that an aspect of the project was behind schedule, the team as a whole reassessed and fine-tuned the division of labor, processing plans, and levels of processing to ensure that the project met deadlines. The metrics were not used for

72. This approach is similar to that reported by Novak-Gustainis in that UNLV recorded metrics for aspects of processing beyond arrangement and description: Novak-Gustainis, "Processing Workflow Analysis for Special Collections." See literature review for studies that present both the value of tracking archival processing actions and methods for recording the metrics. 
individual staff evaluation but only as a way to show when processes and assignments needed adjustment.

Ongoing awareness of metrics also supported agility. For example, a few months into the project, the team recognized an opportunity to more appropriately describe collection materials about Native American nations. However, the proposed extra description would require extensive research time, which was not built into the project timeline. Because this was important to the team, they ran trials to predict how much time it would take to research and document 180 self-identifying names of Native American nations. They then assessed the archival processing metrics for all project collections up to that date. Metrics indicated the team was ahead of schedule and could afford to spend less time per week (two to three hours) on processing, thus carving out time to research and standardize the names. By primarily describing Native American nations using the nations' own names for themselves, the team more accurately and respectfully described the materials. By also including the anglicized names by which the nations might be better known to researchers, they increased search optimization. Access to current metrics, coupled with an agile processing approach, freed the team from dogmatically following the processing plan and enabled them to seize opportunities that enhanced the end result.

\section{Determining the Suitability of Agile Practices}

Overall, UNLV's experience with America's Great Gamble is in harmony with studies that show a correlation between agile factors and project success. While the proponents of agile methodologies primarily focus on how agile practices contribute to project success, they also acknowledge that these practices are not universally applicable. Project environments and teams differ from one project to the next; therefore, agile factors will not lead to success in all scenarios. Some studies conclude that, rather than implementing purely agile methods, it may be just as effective, or even more effective, to integrate agile and traditional practices in a hybrid approach. ${ }^{73}$ Mario Špundak reminds readers that "there is no silver bullet" and that the "methodology should be adapted to the project and not vice versa." 74

When considering an agile project management approach, it is important to be aware of possible challenges to implementing agile practices. For example, Conforto et al. note barriers to agile practices such as an inability to co-locate team members and difficulty assembling multidisciplinary teams with the neces-

73. See Fernandez and Fernandez, "Agile Project Management," 16; Mario Špundak, "Mixed Agile/ Traditional Project Management Methodology: Reality or Illusion?” Procedia: Social and Behavioral Sciences 119 (2014): 946; Serrador and Pinto, "Does Agile Work?” 1042; Conforto et al, "Can Agile Project Management Be Adopted by Industries Other Than Software Development?” 31.

74. Špundak, "Mixed Agile/Traditional Project Management Methodology," 946. 
sary competencies. ${ }^{75}$ Augustine et al. also list a number of specific difficulties with agile-style methods, including the potential for senior staff to resent an egalitarian team structure and the ineffectiveness of a "light touch" management technique when applied to unmotivated or unproductive team members. ${ }^{76}$ In counterpoint to the success factors they examine, Chow and Cao list nineteen "failure factors" that hinder agile practices, such as lack of executive sponsorship, lack of project management competence, lack of a progress tracking mechanism, and ill-defined project planning, just to name a few. ${ }^{77}$

In response to extreme enthusiasm for agile methods, some practitioners have expressed concern regarding the fervor around the agile movement. They fear that managers may adopt practices simply because they are branded as "agile." Fernandez and Fernandez cite G. Alleman, who "believes that managing projects with agility is no more than simply using process areas appropriately and with intelligence."78 The fact that UNLV's implementation of agile-style practices grew out of common sense, without awareness of established agile methodologies, lends credence to this idea. The notion that agile is first and foremost a set of values that can inform any number of practices is confirmed by one of the movement's luminaries. The coauthors of the Manifesto for Agile Software Development were asked to reflect on the agile movement a decade after they had written the Manifesto. When asked, "What is agile's place outside of software development?" one of the authors, Arie van Bennekum, replied, "Agile is holistic and applicable anywhere in business or life, I use it as a concept wherever I am and for whatever I do." ${ }^{\prime 79}$ Fundamentally, agile concepts and values are widely relevant; however, those values must be expressed in practice before they can have any impact. When considering agile methodologies, project managers should carefully select the practices that best fit each project, but they should strive to apply core agile values-flexibility, trust, empowerment, and collaboration—as much as possible.

\section{Areas for Future Exploration}

The core values of agile project management are clearly compatible with efficient archival processing methods. Although the agile-style methods piloted at UNLV might serve as a springboard for experimentation at other institutions, a broad study is needed to determine the place of agile project management in the special collections and archives community. To close the gap in the literature, lines of inquiry might begin with ascertaining whether or not information professionals

75. Conforto et al., "Can Agile Project Management Be Adopted by Industries Other Than Software Development?” 30-31.

76. Augustine et al., "Agile Project Management," 89.

77. Chow and Cao, "A Survey Study of Critical Success Factors," 963.

78. Fernandez and Fernandez, "Agile Project Management," 15.

79. Michelle Bowles Jackson, "Agile: A Decade In," PM Network 26, no. 4 (Apr. 2012): 62. 
are deploying intentional and holistic methods for managing archival processing projects and, if so, are they using traditional, agile, or hybrid models? The next step would be to gather data and analyze whether or not the methods demonstrate measurable success for projects and if the methods have been successfully extended from project work to daily archival processing operations. Far from being prescriptive regarding the implementation of agile project management, the purpose of this paper is to raise awareness of its potential and encourage professional dialog on the subject.

\section{Conclusion}

The importance of holistic project planning and management is underscored in library project management literature and illustrated to a small degree by the UNLV grant project America's Great Gamble. The literature indicates that information professionals are regularly and successfully managing a variety of projects-some are following established project management processes, but many are managing projects less formally. ${ }^{80}$ The lack of case studies on project management in the field of archives and manuscripts suggests that, although archivists are definitely managing projects, they may not be giving project management theory the attention it deserves.

Given that there are strong correlations between project management practices and project success rates, archival projects should be managed intentionally. Project management should be an integral part of the infrastructure of archival projects. Information professionals embarking on archival processing projects will increase their odds of success if they approach their projects holistically rather than focusing solely on archival processing. As information professionals develop project management strategies for archival projects, agile methodologies are worth considering. Agile methodologies are compatible in principle and practice with iterative team-based archival processing techniques.

Agile factors are clearly linked to project success, but even managers who wholeheartedly espouse agile methods recognize that each project's management strategy must be developed to fit the circumstance. Agile methods do not need to be adopted wholesale-managers can assimilate selected agile practices into existing methods to augment success. By considering all project components-project scope and goals, organizational mission and culture, processing techniques, staff skills and behaviors, technological support, schedule, and budget - managers can develop a project management strategy to suit each project. By proactively adapt-

80. When asked the survey question, "How would you characterize the approach to managing projects in your library?" 43.5 percent of respondents answered "Ad-hoc"; Horwath, "How Do We Manage?" $21-22$. 
ing the strategy to changing conditions and priorities throughout the project, the manager can guide the project to its best possible outcome.

In the world of project management, the term agile means far more than being flexible and responsive to change. Agile principles and practices release the project team from a fixed top-down plan and empower them to imagine and implement improvements to a plan, process, and result that they own. Freed from the limitations of the initial plan, an agile-style team can seize unexpected opportunities to meet project goals. They thereby have the potential to deliver an even better outcome than originally conceived. In the context of archival processing project management, an agile approach may lead to improved processing procedures, increased effectiveness and efficiencies in the conservation, arrangement, and description of collection materials, and other unforeseen ways to enhance access to collections.

\section{RESPONSE \& RESPONSIBILITY} SPECIAL COLLECTIONS AND CLIMATE CHANGE

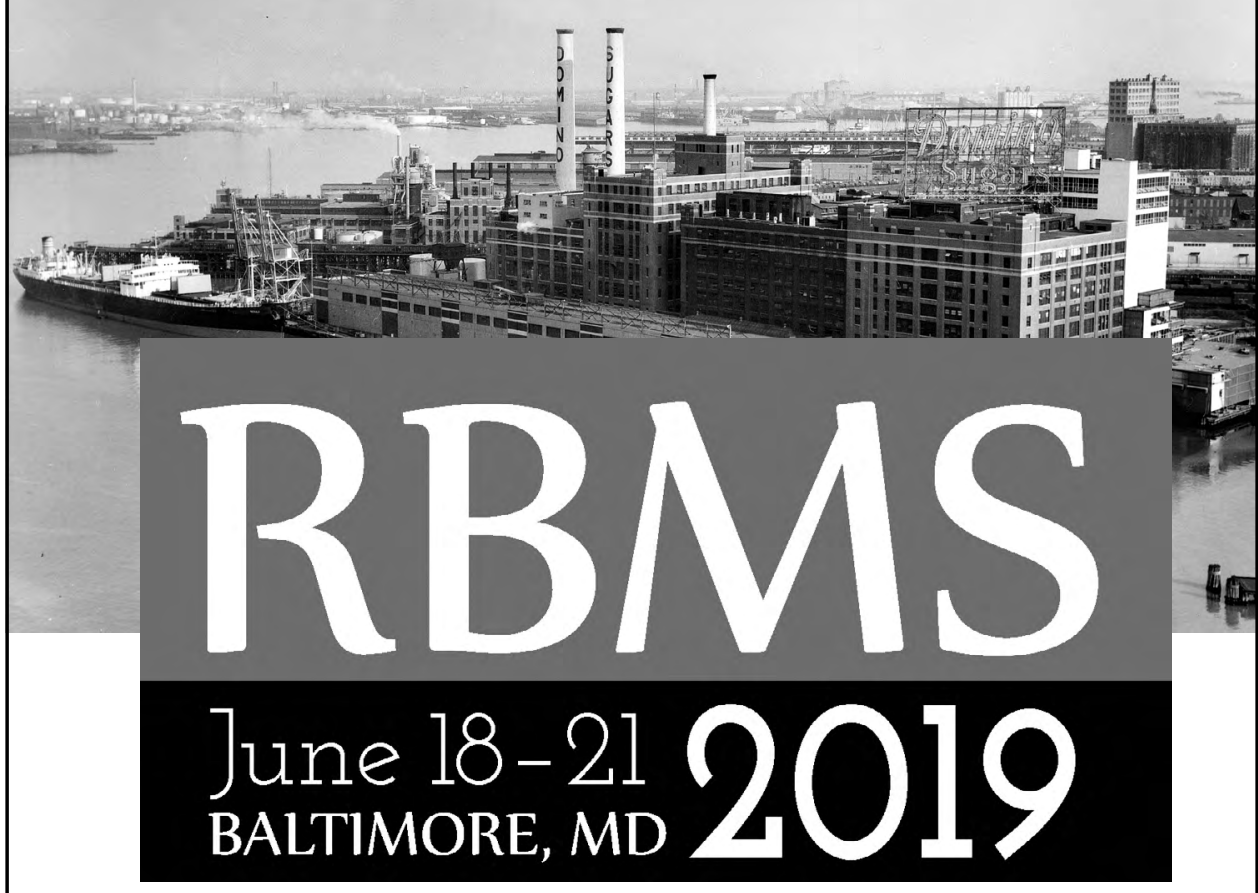

\section{Registration opens in February.}

http://conference.rbms.info/2019 